\title{
Efeito da perda de peso sobre a hemodinâmica renal em portadores da síndrome metabólica
}

\author{
Weight loss improves renal hemodynamics in patients with \\ metabolic syndrome
}

\begin{abstract}
Authors
Danielle Guedes Andrade Ezequiel ${ }^{1}$ Monica Barros Costa ${ }^{1}$ Alfredo Chaoubah ${ }^{1}$ Rogerio Baumgratz de Paula $^{1}$
\end{abstract}

${ }^{1}$ Universidade Federal de Juiz de Fora - UFJF.

Submitted on: 07/21/2011 Approved on: 09/22/2011

Correspondence to: Danielle Guedes Andrade Ezequiel

Fundação IMEPEN

Rua José Lourenço Kelmer, 1.300/SL - São Pedro Juiz de Fora - MG - Brazil Zip code 36036-330 E-mail: daniezequiel@ hotmail.com

This study was undertaken at Núcleo Interdisciplinar de Estudos e Pesquisas em Nefrologia - NIEPEN of UFJF.

The authors report no conflicts of interest.

\section{Resumo}

Objetivo: No presente artigo, investigou-se o impacto da redução do peso corporal na excreção urinária de albumina e na depuração da creatinina em indivíduos obesos com síndrome metabólica. Métodos: Trinta e cinco indivíduos foram submetidos à dieta hipocalórica por um período de 12 semanas, visando uma redução mínima de 5\% do peso corporal. Os voluntários foram submetidos à avaliação metabólica (teste oral de tolerância à glicose, dosagens de lípides plasmáticos e ácido úrico) e à avaliação de parâmetros hemodinâmicos renais (depuração da creatinina e excreção urinária de albumina), antes (fase 1) e após 12 semanas de dieta hipocalórica (fase 2). Resultados: Após o período de intervenção, os voluntários foram divididos em dois grupos: indivíduos que atingiram o alvo para redução de peso (respondedores: $\mathrm{R}, \mathrm{n}=14$ ) e pacientes que não atingiram a meta para redução de peso (não-respondedores: $\mathrm{NR}, \mathrm{n}=21$ ). Indivíduos do Grupo R apresentaram melhora do perfil lipídico, da redução da excreção urinária de albumina (mediana $=162.5 \mathrm{mg} / 24$ horas, variação: 0,8 a $292 \mathrm{mg} / 24$ horas, na fase 1 para 10,4 mg/24 horas, variação: 1,6 a $22,4 \mathrm{mg} / 24$ horas, na fase 2), além de redução significante da depuração da creatinina $(121,4 \pm 66,5 \mathrm{~mL} / \mathrm{min}$. para $92,9 \pm 35,6 \mathrm{~mL} / \mathrm{min} ., \mathrm{p}=0,001)$. No Grupo $\mathrm{NR}$, não foram observadas diferenças estatisticamente significantes entre as fases $1 \mathrm{e}$ 2 do estudo. Conclusão: A redução do peso corporal teve impacto positivo na hemodinâmica renal, reduzindo a excreção urinária de albumina e a hiperfiltração glomerular em indivíduos obesos com síndrome metabólica.

Palavras-chave: Obesidade. Síndrome X Metabólica. Albuminúria. Falência Renal Crônica.

\section{Abstract}

Objective: We investigated the impact of weight loss on urinary albumin excretion (UAE) and creatinine clearance in obese patients with metabolic syndrome. Methods: Thirty-five obese patients undertook a 12 -week calorierestricted diet. The patients underwent a metabolic (oral glucose tolerance test, plasma lipids, and uric acid) and renal hemodynamic evaluations (creatinine clearance and urinary albumin excretion) before (phase 1), and after the 12week diet (phase 2). Results: After the dietary intervention, the subjects were divided into two groups: patients who achieved the target weight reduction ( $R$ : responders, $\mathrm{n}=14$ ), and patients who did not (NR: non-responders, $\mathrm{n}=21$ ). The patients in Group R showed an improvement in lipid profile, a decrease in UAE (median $=162.5 \mathrm{mg} / 24$ hours, range: 0.8 to $292 \mathrm{mg} / 24$ hours, at phase 1 versus $10.4 \mathrm{mg} / 24$ hours, range: 1.6 to $22.4 \mathrm{mg} / 24$ hours, at phase 2 ), and a significant reduction in creatinine clearance $(121.4 \pm 66.5 \mathrm{~mL} / \mathrm{min}$. in phase 1 to $92.9 \pm 35.6 \mathrm{~mL} / \mathrm{min}$. at the end of phase $2, p=0.001)$. In Group NR, no statistically significant differences were observed between phases 1 and 2. Conclusion: Body weight reduction has a positive impact on renal hemodynamics, decreasing urinary albumin excretion as well as glomerular hyperfiltration in obese patients with metabolic syndrome.

Keywords: Obesity. Metabolic Syndrome X. Albuminuria. Kidney Failure, Chronic. 


\section{INTRODUCTION}

Metabolic syndrome (MS) is a clustering of risk factors for cardiovascular diseases (CVD), such as: hypertension, hypertriglyceridemia, low HDLcholesterol levels, disorders of glucose metabolism, and insulin resistance. A number of associated conditions are included in the MS spectrum, such as: abdominal obesity, systemic inflammatory activation, endothelial dysfunction, non-alcoholic fatty liver disease, hyperuricemia, polycystic ovarian syndrome, and microalbuminuria. ${ }^{1,2}$

Consequently, the diagnosis of MS identifies patients who are at increased risk for type 2 diabetes mellitus and CVD. ${ }^{3-5}$ In the last few years, the potential for MS to trigger renal damage and accelerate the progression of pre-existing nephropathy has become a focus of research. ${ }^{6-8}$ In a study of 202 incident dialysis patients, Young et al. reported a MS prevalence of nearly $70 \%$ at the initiation of renal replacement therapy and found that MS was particularly prevalent among patients who were diabetic, female, and white-colored. ${ }^{9}$ Several other epidemiological studies have demonstrated a positive correlation between MS and microalbuminuria. ${ }^{7,8,10}$ Chen et al. reported an association between the number of MS components and the development of chronic kidney disease (CKD) in a study of 6,217 individuals. However, a cause-effect relationship between MS and CKD could not be established, due to the cross-sectional design of the study. ${ }^{11}$ These findings were further confirmed in a large prospective study, which found a positive correlation between the prevalence of CKD and the number of MS components. ${ }^{8}$ Overall, these studies suggest that MS can influence the development of CKD, although the underlying mechanisms are not well understood. In this study, we hypothesized that modifying a key component of the MS, namely obesity, could attenuate renal damage.

The aim of this study was to investigate the impact of weight loss on creatinine clearance and urinary albumin excretion (UAE) in non-diabetic obese patients with MS.

\section{Methods}

\section{PATIENTS}

Non-diabetic patients with MS were recruited from an outpatient clinic at the Division of Nephrology of the Federal University of Juiz de Fora, in Brazil. MS was defined according to the criteria of the National Cholesterol Education Program Adult Treatment
Panel III (NCEP-ATPIII). ${ }^{12}$ The main exclusion criteria were: fasting plasma glucose $>126 \mathrm{mg} / \mathrm{dL}$ or history of diabetes mellitus; hypertension stage 2 or 3; glomerulonephritis; CKD stages 3, 4, or 5; severe heart or lung disease, and pregnancy. Fifty-five patients were evaluated, and 35 individuals, aged between 20 and 65 years-old, were considered eligible for inclusion. The study protocol was revised and approved by the Human Subjects Review Committee of the Federal University of Juiz de Fora (approval number 273/2006). All subjects provided the written informed consent.

\section{Methods}

The study was divided into two phases: 1 (baseline) and 2 (intervention).

\section{PhASe 1 (WEeKs 1 TO 4)}

At the first study visit (day 0), a full medical history (demographic data and lifestyle: smoking, alcohol consumption, and physical activity) was taken and a clinical examination was performed. Blood pressure measurement had been performed with the patient seated quietly for at least five minutes with feet on the floor, and his/her arm supported at the heart level. An aneroid equipment coupled with an appropriately sized cuff (cuff bladder encircling at least $80 \%$ of the arm) was used to ensure accuracy. The mean of the last two of three measurements was used for analysis. Blood samples were taken to determine plasma glucose levels, both after fasting and two hours after a 75 -g oral glucose overload (oral glucose tolerance test - OGTT), as well as levels of plasma insulin, TSH, creatinine, total cholesterol, HDL-cholesterol, triglycerides, and uric acid. All patients had fasted overnight for 12 hours prior to sampling. A colorimetric method was used to measure plasma glucose, serum creatinine, total cholesterol, HDL-cholesterol, triglycerides, and uric acid levels. The insulin concentration was measured in duplicate by a chemiluminescence assay (Beckman Coulter, N. Harbor, USA). The Friedewald formula was used to calculate LDL-cholesterol levels. HOMA index (HOMA-IR) was calculated using the formula HOMA-IR = glucose $(\mathrm{mmoL} / \mathrm{L}) \times$ insulin $(\mathrm{U} / \mathrm{mL}) / 22.5 .{ }^{13}$

At visit 2 (day 14), the preliminary results were evaluated and 24-hour urine samples were collected in duplicate for measurement of microalbuminuria. Urinary albumin was measured by nephelometry (Dade Behring/Newark DE19714, USA). Creatinine clearance was estimated using the Cockcroft-Gault formula, which was corrected for the body surface 
area. ${ }^{14}$ The subjects were kept free of any medication (statins; antihypertensive, antiobesity and antiinflammatory drugs) over the entire study period. The only medications allowed during the study were analgesics, such as dipyrone and hioscin.

At visit 3 (day 28), each patient was evaluated by a registered dietitian with expertise in medical nutrition therapy with the aim of achieving a weight loss of at least $5 \%$ from baseline and a 12 -week calorierestricted diet consisting of $50 \%$ carbohydrate, 20 to $25 \%$ protein, and 25 to $30 \%$ fat was initiated.

\section{PHASE 2 (WEeks 5 TO 16)}

Patients were evaluated by the dietitian every two weeks. All the participants were asked not to join any kind of fitness program throughout the study. At the final visit all laboratory tests were repeated. At the end of phase 2 , patients were divided into two groups: responders, who had achieved at least a $5 \%$ reduction in body weight (Group $\mathrm{R}, \mathrm{n}=14$ ); and non-responders, who had not achieved the target weight reduction (Group NR, n = 21).

\section{StATISTICAL ANALYSIS}

The SPS, version 13.0, software package (SPSS, Chicago, IL, USA) was used to perform the statistical analyses. Normally distributed data were expressed as means and standard deviations (SD). Paired and unpaired Student's $t$-tests were used to compare variables within and between the two groups (R and NR), respectively. Data with a skewed distribution were expressed as medians (ranges) and they were compared using the Mann-Whitney's test. Results were considered significant when $\mathrm{p}$ was less than 0.05 .

\section{RESULTS}

Thirty-five patients were included in the study. The mean age was $43.0 \pm 11.4$ years-old and 30 of the patients $(86 \%)$ were female. The median duration of obesity was 10.0 years-old (range, 1 to 40 ) and of hypertension was 2.0 years-old (range, 0.1 to 20). The body mass index (BMI) was $35.0 \pm 5.5 \mathrm{~kg} / \mathrm{m}^{2}$. All of the patients had waist circumference above the cut-off point (mean: $111.6 \pm 11.0 \mathrm{~cm}$ ). Twenty-three patients $(66 \%)$ had mild hypertension with a systolic blood pressure $(\mathrm{SBP})$ of $139.3 \pm 15.3 \mathrm{mmHg}$, and a diastolic blood pressure (DBP) of $90.1 \pm 9.0 \mathrm{mmHg}$. Total cholesterol and HDL-cholesterol means were $201.2 \pm 40.6 \mathrm{mg} / \mathrm{dL}$ and $42.0 \pm 9.7 \mathrm{mg} / \mathrm{dL}$, respectively. Triglyceride levels were $196.3 \pm 88.5 \mathrm{mg} / \mathrm{dL}$, and most patients $(80 \%)$ had levels above the cut-off. Fasting plasma glucose levels were $92.3 \pm 11.0 \mathrm{mg} / \mathrm{dL}$; a two-hour post-glucose load values were $117.1 \pm 32.2 \mathrm{mg} / \mathrm{dL}$, and 16 patients $(46 \%)$ had impaired glucose tolerance. Median HOMA-IR was 2.8 (range, 0.45 to 11.4 ) and 19 patients $(54 \%)$ had values above 2.5. Creatinine clearance was $115.3 \pm 38.6 \mathrm{~mL} / 24$ hours. Microalbuminuria, defined as a UAE of $>30 \mathrm{mg} / 24$ hours, was detected in 22 patients $(63 \%)$, with a median level of $46.7 \mathrm{mg} / \mathrm{dL}$ (range, 1.5 to 292 ).

\section{DEMOGRAPHIC AND CLINICAL FEATURES OF RESPONDERS AND NON-RESPONDERS}

No significant differences were observed between Group R and Group NR in age, gender, BMI, waist circumference, or duration of obesity or hypertension (Table 1).

At the end of phase $2,40 \%$ of the patients (14/35) had achieved the target weight loss and were assigned to Group R. The mean weight reduction in Group R was $8.5 \pm 2.2 \mathrm{~kg}(9.4 \%$ from baseline $)$ and abdominal circumference decreased from $114.5 \pm 16.1 \mathrm{~cm}$ to $103.6 \pm 10.2 \mathrm{~cm}(\mathrm{p}=0.001)$. In Group NR, patients gained $1.0 \pm 3.5 \mathrm{~kg}$, and there was no significant changes in the abdominal circumference $(111.1 \pm 9.2 \mathrm{~cm}$ versus $109.3 \pm 10.3 \mathrm{~cm}, \mathrm{p}=0.304)$.

\section{Tabela 1 Demographic AND CLINICAL FEATURES OF RESPONDERs (Group R) AND NON-RESPONDERS (GROUP NR)}

\begin{tabular}{lccc} 
Parameters & Group R $(\mathrm{n}=14)$ & Group NR $(\mathrm{n}=21)$ & $\mathrm{p}$-value \\
\hline Age $(\text { years })^{\dagger}$ & $44.3 \pm 10.3$ & $43.9 \pm 12.1$ & 0.919 \\
Male/Female $(\mathrm{n})$ & $2 / 12$ & $3 / 18$ & 1.000 \\
Duration of obesity (years) $^{\ddagger}$ & $10.0(1-25)$ & $3.0(0.8-40)$ & 0.709 \\
Duration of hypertension (years) $^{\ddagger}$ & $0.2(0.1-20)$ & $3.0(0.1-20)$ & 0.236 \\
$\mathrm{BMI}\left(\mathrm{kg} / \mathrm{m}^{2}\right)^{\dagger}$ & $36.3 \pm 6.7$ & $34.2 \pm 4.7$ & 0.276 \\
${\text { Waist circumference }(\mathrm{cm})^{\dagger}}^{+}$ & $114.5 \pm 16.1$ & $111.1 \pm 9.2$ & 0.174
\end{tabular}

${ }^{\dagger}$ values expressed as means \pm standard deviation; ${ }^{\ddagger}$ values expressed as median and range; ${ }^{\S} \mathrm{BMI}$ : body mass index. 
Following weight loss, Group R patients showed a statistically significant decrease in DBP, from $90.0 \pm 7.5 \mathrm{mmHg}$ to $78.2 \pm 8.2 \mathrm{mmHg}(\mathrm{p}=0.007)$, and a trend towardsa reduction in SBP, from $135.0 \pm 18.7 \mathrm{mmHg}$ to $123.6 \pm 7.4 \mathrm{mmHg}(\mathrm{p}=0.059)$. Although Group NR patients failed to lose weight, SBP decreased from $140.1 \pm 13.4 \mathrm{mmHg}$ to $129.8 \pm 9.8 \mathrm{mmHg}$ following nutritional intervention $(\mathrm{p}=0.010)$, and a non-significant reduction in DBP was observed $(90.0 \pm 10.2 \mathrm{mmHg}$ to $85.9 \pm 7.3 \mathrm{mmHg} ; \mathrm{p}=0.143$ ).

\section{Metabolic parameters in Responders AND NON-RESPONDERS}

No significant differences in fasting plasma glucose and two-hour OGTT glucose levels were observed between Groups R and NR in phase 1 or after phase 2. At the end of phase 2, a trend towards a decrease in HOMAIR was observed in Group R $(3.0 \pm 2.1$ at phase 1 to $1.6 \pm 0.66$ at the end of phase 2), with $\mathrm{p}=0.057$. In Group R, a statistically significant decrease in triglyceride levels $(\mathrm{p}=0.031)$ and an increase in HDLcholesterol $(\mathrm{p}=0.039)$ were observed. Uric acid levels showed a trend towards a reduction $(\mathrm{p}=0.057)$, as seen in Table 2. For Group NR, no changes in these metabolic parameters were observed from phase 1 to 2 (Table 3). Taken together, these results indicate that there was an improvement in the metabolic status of patients in Group R but not in Group NR.
RENAL HEMOdYNAMIC PARAMETERS IN RESPONDERS AND NON-RESPONDERS

On one hand, in Group R, UAE decreased significantly from 162.5 (range, 0.8 to 292.0) to $10.4 \mathrm{mg} / 24$ hours (range, 1.6 to 22.4) following weight loss $(\mathrm{p}=0.010)$. Most patients in this group $(10 / 14)$ showed a significant decrease in UAE. On the other hand, no change in UAE was observed in Group NR between phase 1 and the end of phase 2 (Figure 1). When microalbuminuria values were compared as categorical data, with normoalbuminuria defined as $<30 \mathrm{mg} / 24$ hours and microalbuminuria

Figure 1. Urinary albumin excretion in $\mathrm{R}$ and $\mathrm{NR}$ Groups, before and after the dietary intervention (phases 1 and 2).

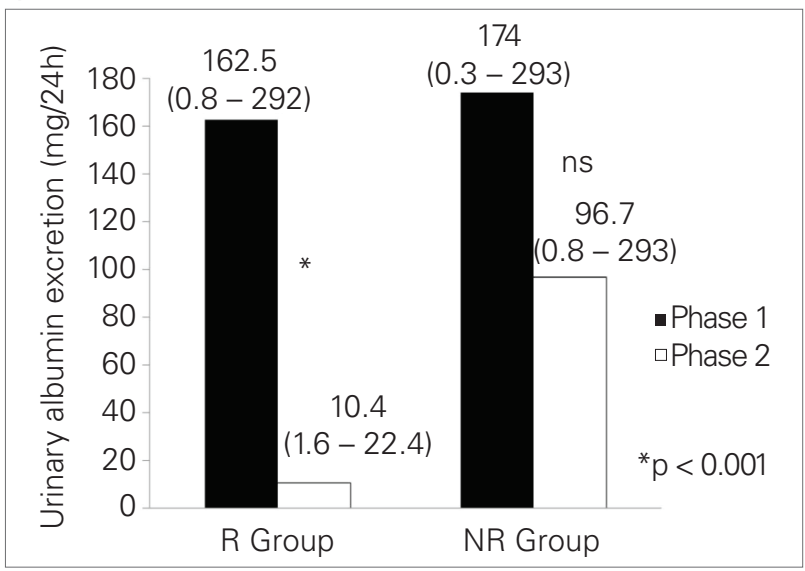

Tabela 2 LABORATORY DATA OF RESPONDERS (GROUP R)

\begin{tabular}{lccc} 
Parameters & Phase 1 & Phase 2 & p-value \\
\hline Fasting glucose $(\mathrm{mg} / \mathrm{dL})$ & $92.8 \pm 10.9$ & $92.6 \pm 13.3$ & 0.976 \\
2-h OGTT glucose $(\mathrm{mg} / \mathrm{dL})^{\dagger}$ & $114.1 \pm 35.8$ & $112.1 \pm 33.9$ & 0.866 \\
HDL $(\mathrm{mg} / \mathrm{dL})^{\ddagger}$ & $42.8 \pm 11.7$ & $51.8 \pm 10.7$ & 0.039 \\
Triglycerides $(\mathrm{mg} / \mathrm{dL})$ & $188.6 \pm 79.4$ & $141.9 \pm 77.9$ & 0.031 \\
Uric acid $(\mathrm{mg} / \mathrm{dL})$ & $4.9 \pm 1.2$ & $4.1 \pm 1.1$ & 0.057 \\
HOMA-IR $^{\S}$ & $3.0 \pm 2.1$ & $1.6 \pm 0.7$ & 0.057
\end{tabular}

${ }^{\dagger}$ OGTT: oral glucose tolerance test; ${ }^{\S} \mathrm{HOMA}-\mathrm{IR}$ : homeostatic model assessment of insulin resistance; ${ }^{\text {HDL: }}$ high-density lipoprotein.

Tabela 3 LABORATORY DATA OF NON-RESPONDERS (GROUP NR)

\begin{tabular}{lccc} 
Parameters & Phase 1 & Phase 2 & p-value \\
\hline Fasting glucose $(\mathrm{mg} / \mathrm{dL})$ & $92.3 \pm 12.9$ & $89.3 \pm 11.9$ & 0.429 \\
2-h OGTT glucose $(\mathrm{mg} / \mathrm{dL})^{\dagger}$ & $119.2 \pm 27.9$ & $117.2 \pm 32.6$ & 0.826 \\
${\text { HDL }(\mathrm{mg} / \mathrm{dL})^{\ddagger}}^{\text {Triglycerides }(\mathrm{mg} / \mathrm{dL})}$ & $43.0 \pm 8.4$ & $41.5 \pm 9.8$ & 0.345 \\
Uric acid $(\mathrm{mg} / \mathrm{dL})$ & $206.0 \pm 98.0$ & $224.0 \pm 140.5$ & 0.278 \\
HOMA-IR $^{\S}$ & $5.1 \pm 0.9$ & $4.7 \pm 1.2$ & 0.145 \\
\hline
\end{tabular}

${ }^{\dagger}$ OGTT: oral glucose tolerance test; ${ }^{\S} \mathrm{HOMA-IR}$ : homeostatic model assessment of insulin resistance; *HDL: high-density lipoprotein. 
defined as $>30 \mathrm{mg} / 24$ hours, results showed that following nutritional intervention, microalbuminuria decreased to the normal range in $9 / 14(64 \%)$ of the patients in Group R compared to only $14 \%$ $(3 / 21)$ in the NR Group $(\mathrm{p}=0.011)$.

As can be seen in Figure 2, creatinine clearance decreased significantly from $121.4 \pm 66.5 \mathrm{~mL} /$ minutes in phase 1 to $92.9 \pm 35.6 \mathrm{~mL} / \mathrm{minutes}$ at the end of phase 2 ( $\mathrm{p}=0.001)$. Conversely, in the NR Group, no significant differences in this parameter were observed in phase 1 compared to phase $2(102.2 \pm 29.9 \mathrm{~mL} /$ minutes versus $97.5 \pm 31.8 \mathrm{~mL} /$ minutes, respectively), as seen in Figure 2.

\section{Discussion}

The worldwide epidemic of obesity-associated MS is a potential risk for cardiovascular morbidity and mortality. In addition, there is emerging evidence that obesity is a major risk factor for kidney damage independent of diabetes or hypertension. Cross-sectional ${ }^{9-11}$ and longitudinal studies ${ }^{7,8}$ have both demonstrated a relationship between components of the MS and risk of developing kidney injury, further suggesting a link between obesity and CKD.

The obese subjects included in the present study had glomerular hyperfiltration and increased urinary albumin excretion, abnormal renal hemodynamics that could potentially lead to kidney damage over the long term. The main finding in the present study is that a slight reduction in body weight ameliorated glomerular hyperfiltration and decreased urinary albumin excretion.

To the authors' knowledge, no studies have addressed non-pharmacological interventions as the sole strategy for nephroprotection in patients with mild obesity, without evidence of significant kidney damage. Most studies have focused on patients with severe

Figure 2. Creatinine clearance in $\mathrm{R}$ and NR Groups, before and after dietary intervention.

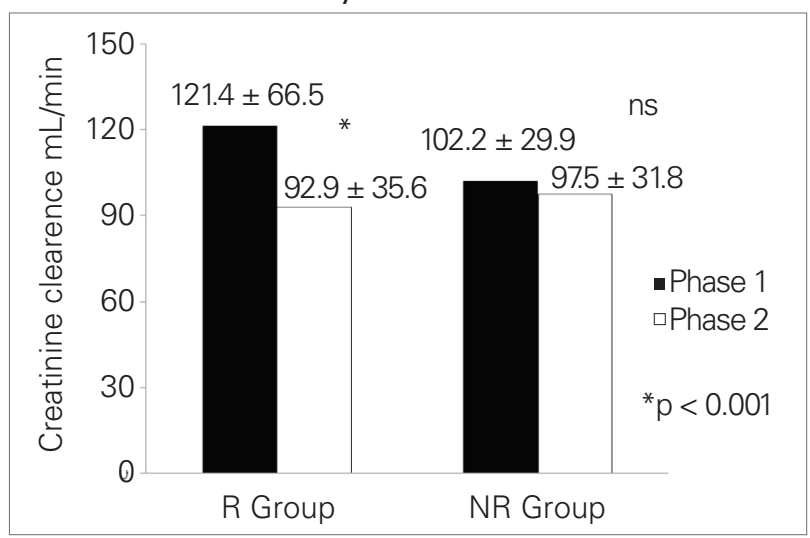

obesity, diabetes, and proteinuric nephropathies. For example, weight loss due to gastroplasty was effective in reducing the glomerular filtration rate (GFR) and albumin excretion in patients with BMI above $38 \mathrm{~kg} / \mathrm{m}^{2} .^{15}$ Similar results have been reported by the present group and by others in morbidly obese patients who underwent bariatric surgery. ${ }^{16-20}$ In obese patients with overt proteinuria, Morales et al. found that caloric restriction led to a $31.2 \pm 37.0 \%$ reduction in the UAE despite achieving only a modest decrease in body weight. ${ }^{21}$ In the present study, we have shown for the first time an improvement in renal hemodynamics in mildly obese patients, with microalbuminuria submitted to a calorie-restricted diet as the sole strategy to lose weight.

The study was not designed to explore mechanisms of obesity-induced kidney damage, but we speculate that hemodynamic changes could play a role in glomerular damage associated with obesity. Previous studies in animal models have shown that, even in the short-term, obesity causes a renal hemodynamic overload with glomerular hyperfiltration, and microalbuminuria. Dogs fed with a high fat diet for five weeks, obesity induced a 30\% increase in the glomerular filtration rate. ${ }^{22}$ This change was associated with an increase in renal blood flow and renal tubular sodium reabsorption, with a secondary increase in renin secretion, which was mediated by stimulation of the macula densa. Glomerulomegaly and increased TGF $\beta_{1}$ expression in the renal interstitium were observed in this model, both of which could explain the early renal damage in obesity. ${ }^{23}$

We speculated that the reduction in blood pressure observed in the current study may have contributed to the decrease in urinary albumin excretion. Hypertension is a hallmark feature of MS and is associated with increased urinary albumin excretion. ${ }^{24}$ In the present study, a $9.4 \%$ decrease in the body weight was associated with a significant reduction in DBP and with a trend towards reduction in SBP. However, it should be noted that the significant reduction in SBP, which also occurred in the NR Group, argues against our hypothesis.

Metabolic mediators may also have contributed to glomerular hyperfiltration in the present study. The relationship between insulin resistance and renal damage in MS deserves attention. Insulin resistance and, consequently, hyperinsulinemia are known to play important roles in the development of atherosclerosis in MS patients, independent of the diagnosis of diabetes. ${ }^{25}$ In an experimental study with Rhesus monkeys, mesangial expansion and increased glomerular volume were observed prior to the development 
of hyperglycemia, which is a finding compatible with the trophic effect of insulin in the mesangial cells. ${ }^{26}$ Similarly, in 12 obese patients with metabolic syndrome, glomerular lesions, such as vascular sclerosis, tubular atrophy, and interstitial fibrosis, could be detected prior to the diagnosis of diabetes mellitus. ${ }^{27}$ In the present study, most of the patients had a high HOMA-IR, which decreased after weight loss, suggesting the presence of insulin resistance. In addition, a significant improvement was found in the metabolic profile after weight loss, with a reduction in triglyceride levels and an increase in HDL-cholesterol. In fact, the triglyceride-HDL ratio is a sensitive indicator of insulin resistance in non-diabetic obese patients, ${ }^{28}$ and it deserves further investigation.

The current study had some limitations, particularly in the small number of subjects enrolled and its non-randomized design. However, it was ethically mandatory to offer nutritional counseling to all the patient population, which prevented us from undertaking a randomized study. These shortcomings were compensated by the study's prospective design and the careful supervision of the dieticians who monitored subject compliance throughout the protocol.

In conclusion, MS subjects have subtle changes in renal hemodynamics that were ameliorated by weight loss. Considering that glomerular hyperfiltration and microalbuminuria in the setting of obesity are risk factors for the development of CKD, this intervention seems to be of remarkable benefit. Long-term studies, which include a larger number of study participants, may lead to the adoption of this strategy for the prevention of kidney damage in obese patients.

\section{AcKNOWLedgments}

This research was supported by Coordenação de Aperfeiçoamento de Pessoal de Nivel Superior (CAPES) and the IMEPEN Foundation.

\section{References}

1. Reaven GM. Banting lecture 1988. Role of insulin resistance in human disease. Diabetes 1988;37:1595607.

2. Alberti KG, Zimmet P, Shaw J. Metabolic syndrome-a new world-wide definition. A consensus statement from the International Diabetes Federation. Diabet Med 2006;23:469-80.

3. Mottillo S, Filion KB, Genest J, et al. The metabolic syndrome and cardiovascular risk. A systematic review and meta-analysis. J Am Coll Cardiol 2010;56:1113-32.

4. Alexander CM, Landsman PB, Teutsch SM, Haffner SM. NCEP-defined metabolic syndrome, diabetes, and prevalence of coronary heart disease among NHANES III participants age 50 years and older. Diabetes 2003;52:1210-4.

5. Ford SE, Li C, Sattar N. Metabolic Syndrome and Incident Diabetes. Diabetes Care 2008;31:1898-904.

6. Bonnet F, Deprele C, Sassolas A, et al. Excessive body weight as a new independent risk factor for clinical and pathological progression in primary IgA nephritis. Am J Kidney Dis 2001;37:720-7.

7. Kurella M, Lo JC, Chertow GM. Metabolic syndrome and the risk for chronic kidney disease among nondiabetic adults. J Am Soc Nephrol 2005;16:2134-40.

8. Tanaka H, Shiohira Y, Uezu Y, Higa A, Iseki K. Metabolic syndrome and chronic kidney disease in Okinawa, Japan. Kidney Int 2006;69:369-74.

9. Young DO, Lund RJ, Haynatzki G, Dunlay RW. Prevalence of the metabolic syndrome in an incident dialysis population. Hemodial Int 2007;11:86-95.

10. Hoehner CM, Greenlund KJ, Rith-Najarian S, Casper ML, McClellan WM. Association of the insulin resistance syndrome and microalbuminuria among nondiabetic Native Americans. The Inter-Tribal Heart Project. J Am Soc Nephrol 2002;13:1626-34.

11. Chen J, Muntner P, Hamm LL, et al. The metabolic syndrome and chronic kidney disease in U.S. adults. Ann Intern Med 2004;140:167-74.

12. National Cholesterol Education Program (NCEP). Expert Panel on Detection, Evaluation, and Treatment of High Blood Cholesterol in Adults (Adult Treatment Panel III): Third Report of the National Cholesterol Education Program (NCEP) Expert Panel on Detection, Evaluation, and Treatment of High Blood Cholesterol in Adults (Adult Treatment Panel III) final report. Circulation 2002;106:3143-421.

13. Matthews DR, Hosker JP, Rudenski AS, Naylor BA, Treacher DF, Turner RC. Homeostasis model assessment: Insulin resistance and beta-cell function from fasting plasma glucose and insulin concentrations in man. Diabetologia 1985;28:412-9.

14. Saracino A, Morrone LF, Suriano V, et al. A simple method for correcting overestimated glomerular filtration rate in obese subjects evaluated by the Cockcroft and Gault formula: A comparison with ${ }^{51} \mathrm{Cr}$ EDTA clearance. Clin Nephrol 2004;62:97-103.

15. Chagnac A, Weinstein T, Herman M, Hirsh J, Gafter U, Ori $Y$. The effects of weight loss on renal function in patients with severe obesity. J Am Soc Nephrol 2003;14:1480-6.

16. Galil Filho JE, Diniz FD, Paula RB, Galil AGS. Repercussões da perda ponderal sobre parâmetros metabólicos e renais: seguimento de 12 meses póscirurgia bariátrica. J Bras Nefrol 2008;30:189.

17. Agrawal V, Khan I, Rai B, et al. The effect of weight loss after bariatric surgery on albuminuria. Clin Nephrol 2008;70:194-202.

18. Navarro-Diaz M, Serra A, Romero R, et al. Effect of drastic weight loss after bariatric surgery on renal parameters in extremely obese patients: long-term follow-up. J Am Soc Nephrol 2006;17(Suppl):213-7.

19. Navaneethan SD, Yehnert H, Moustarah F, Schreiber MJ, Schauer PR, Beddhu S. Weight loss interventions in chronic kidney disease:a systematic review and metaanalysis. Clin J Am Soc Nephrol 2009;4:1565-74. 
20. Afshinnia F, Wilt TJ, Duval S, Esmaeili A, Ibrahim $\mathrm{HN}$. Weight loss and proteinuria: systematic review of clinical trials and comparative cohorts. Nephrol Dial Transplant 2010;25:1173-83.

21. Morales E, Valero MA, Leon M, Hernández E, Praga M. Beneficial effects of weight loss in overweight patients with chronic proteinuric nephropathies. Am J Kidney Dis 2003;41:319-27.

22. de Paula RB, da Silva AA, Hall JE. Aldosterone antagonism attenuates obesity-induced hypertension and glomerular hyperfiltration. Hypertension 2004;43:41-7.

23. Henegar JR, Bigler SA, Henegar LK, Tyagi SC, Hall JE. Functional and structural changes in the kidney in the early stages of obesity. J Am Soc Nephrol 2001;12:1211-7.

24. Mulè G, Nardi E, Cottone S, et al. Influence of metabolic syndrome on hypertension-related target organ damage. J Intern Med 2005;257:503-13.
25. Mykkanen L, Zaccaro DJ, Wagenknecht LE, Robbins DC, Gabriel M, Haffner SM. Microalbuminuria is associated with insulin resistance in nondiabetic subjects: the insulin resistance atherosclerosis study. Diabetes 1998;47:793-800.

26. Cusumano AM, Bodkin NL, Hansen BC, etal. Glomerular hypertrophy is associated with hyperinsulinemia and precedes overt diabetes in aging Rhesus monkeys. Am J Kidney Dis 2002;40:1075-85.

27. Alexander MP, Patel TV, Farag YM, Florez A, Rennke HG, Singh AK. Kidney pathological changes in metabolic syndrome: a cross-sectional study. Am J Kidney Dis 2009;53:751-9.

28. Brehm A, Pfeiler G, Pacini G, Vierhapper H, Roden M. Relationship between serum lipoprotein ratios and insulin resistance in obesity. Clin Chem 2004;50:2316-22. 